\title{
Revisitando a dança educativa moderna de Rudolf Laban
}

\author{
Isabel A. Marques
}

\section{Revisitando Rudolf Laban}

$\gamma$

araljai vereknyei esliget falyi Laban Rezso Keresztelo szent Janos Attila, ou Rudolf Laban, como mais tarde ficou mundialmente conhecido, começou seu trabalho de pesquisa e criação na Europa, no início do século XX. Seu carisma, senso de humor, dedicação e entusiasmo, aliados à sua intuição, avidez intelectual e observação, fizeram dele não somente um grande 'mestre' da dança, mas uma pessoa muito querida e admirada por seus contemporâneos.

Para o público brasileiro, no entanto, após um século, o trabalho e as contribuiçōes de Rudolf Laban para as áreas de arte e ensino ainda são abstraçōes carregadas de jargões, de idéias inacabadas, de conceitos mal definidos. Método e técnica, dança e educação contrapõemse e confundem-se; os caminhos percorridos pelos princípios e idéias de Laban no Brasil desde a década de 1940 carecem ainda de um olhar mais crítico, contextualizado, contemporâneo.

Os estudos e as propostas de Laban trazem consigo marcas de uma época, de um modo de pensar e de agir característicos da modernidade européia. Em plena 'pós-modernidade', é mister que seja revisitado, não somente para compreendê-lo em seu contexto sócio-político-cultural, mas principalmente para que possa ser inserido de forma não ingênua no contexto artístico e educacional brasileiro. ${ }^{1}$

O estudo aprofundado e minucioso sobre o movimento humano empreendido por Laban tem até hoje oferecido contribuiçôes brilhantes para as áreas de Dança, Teatro, Psicologia, Antropologia, Sociologia, Saúde - para citar algumas. Foram, talvez, suas contribuiçōes para $\mathrm{a}$ área de Educação as mais reconhecidas e amplamente difundidas em várias partes do mundo.

Por trás do professor intuitivo, dedicado e observador, no entanto, repousava primordialmente um artista, preocupado com as questôes de sua época, com a expressividade do ser humano, com a espiritualidade da arte. Laban, portanto, antes de dialogar com educadores, dialogou com artistas e com o público, dedicando-se incansavelmente a estudar a arte do movimento sem finalidades explicitamente educacionais ou escolares.

No Brasil, Laban, o artista, também chega às prateleiras antes do educador. Em 1978,

Doutora em Educação pela USP, diretora do Caleidos Cia. de Dança e do Caleidos Arte e Ensino. Autora do livro Ensino de Dança Hoje (São Paulo: Ed. Cortez, 2001, 2a ed.).

1 Neste artigo não discutiremos o binômio modernidade-pós-modernidade em Rudolf Laban. Para tanto, veja Marques, 1999. 
mesma data em que Lisa Ullmann, discípula de Laban por mais de vinte anos, veio ao Brasil, o livro Dominio do Movimento, publicado pela primeira vez em 1950, é traduzido e publicado em português. Somente em 1990, com 42 anos de atraso em relação à Inglaterra, o público brasileiro pôde conhecer o educador Laban, com a publicação de Dança educativa moderna.

A difusão e desenvolvimento dos trabalhos e das idéias de Laban no Brasil, portanto, fizeram-se principalmente pelo corpo-a-corpo, pelos contatos e buscas individuais de artistas e educadores: termos foram cunhados, interpretações pessoais foram passadas adiante nem sempre com o rigor necessário, práticas freqüentemente foram alicerçadas em conceitos imprecisos, deixando hiatos teóricos e práticos que persistem ainda hoje. Essas lacunas tornaram-se questões que sugerem um caminho de discussão:

- Laban é só Educação?

- existe mesmo um "método Laban"?

- até que ponto os estudos de Laban são uma "técnica"?

\section{Dicotomia entre a arte e a educação}

A sistematização do trabalho educacional de Rudolf Laban começa a ser esboçada em livro em 1926, sendo abortada pelo governo Nacional Socialista da Alemanha em 1930. Nessa época, eram inúmeras as escolas baseadas nos princípios de Laban em toda a Europa. Laban visitava suas escolas no máximo uma vez por mês, confiando a seus ex-alunos e performers portadores ou não do "Laban Diploma" - a continuidade de seu trabalho. Em 1936, as propostas de Laban contra os treinamentos ginásticos e a padronização de corpos em prol da expressão individual do ser humano são consideradas adversas às do regime nazista, resultando no fechamento de suas escolas e na partida de Laban para a Inglaterra.

Somente em 1948, portanto dez anos antes de sua morte, já na Inglaterra, é que Laban escreve Dança educativa moderna, com a intenção de sistematizar melhor suas idéias e conhecimentos para pais e professores. Nesse livro, Laban deixa clara sua devoção e crença na educação através da arte do movimento - ou da dança - associada à liberdade de comunicação e expressão e, portanto, fonte e caminho para a vida, como diria Laban.

Em meados de 1940, Maria Duschenes chega ao Brasil após breve estada na Inglaterra, onde tomou contato com os princípios de Laban (de 1937 a 1939), difundindo-o essencialmente nos meios educacionais que freqüentava. Assim, mesmo tendo sido utilizado na produção de espetáculos na década de 1970 e na educação de alguns profissionais de dança, Laban acaba entrando no Brasil - via Maria Duschenes - pela porta da Educação, criando alianças profundas com o ensino-aprendizado e com os processos escolares e terapêuticos (Navas e Dias, 1992). Essa talvez seja uma das razões pelas quais até hoje o senso comum ainda reze que "Laban é Educação" e, principalmente, educação para crianças.

Por outro lado, já nos primeiros capítulos de Dança educativa moderna, o próprio Laban estabelece a grande dicotomia entre a Arte e a Educação. Reforçado por Lisa Ullmann, no posfácio de 1963, os dois afirmam com intensidade que a função da dança na escola não é formar artistas, ou mesmo "danças sensacionais", mas pessoas livres e capazes de expressar em atitudes criativas e conscientes o fluxo natural do movimento humano (Ullmann, 1990, p. 108-10).

A ênfase no processo em detrimento do produto enfatizada por Laban e por seus seguidores traz à tona velhas (sempre novas) questôes para o ensino de dança nas escolas. É possível ensinar arte sem que se vislumbre o produto? $\mathrm{O}$ conhecimento em arte é viável $\mathrm{e}$ significativo dando-se somente pela experimentação de processos? As relaçôes entre arte, indivíduo e sociedade são possíveis sem a realização do produto estético?

Para os educadores da época de Laban, a questão central, no entanto, era outra: "estamos ensinando dança ou ensinando pessoas?” (Preston- 
Dunlop \& Lahusen, 1990, p. 48). Sem sombra de dúvida, para Laban, o papel da educação era ensinar pessoas, era "[...] ajudar o ser humano por meio da dança a achar uma relação corporal com a totalidade da existência" (Ullmann, 1990, p. 107). O discurso escola-novista de Laban, condizente com o dos pensadores de sua época, não o permitia perceber a estreita e indispensável relação entre a arte profissional e a arte trabalhada com leigos, principalmente em se tratando de crianças. A dicotomia entre a arte e a educação era perfeitamente aceitável e até mesmo louvável, pois o mundo da dança apresentava-se até então altamente codificado, pronto, inabalável, o que feria profundamente seus ideais de criação e transformação do ser humano por meio da dança. Para Laban, assim como para muitos educadores da época, processo criativo e apreciação/produção eram mutuamente excludentes (Marques, 1997).

Essas idéias de Laban, datadas da primeira metade do século XX, deixaram marcas profundas nas práticas e discursos do ensino de dança no Brasil. Não é somente Laban que acreditava na dissociação entre o mundo da produção artística profissional e o mundo da educação escolarizada: grande parte do professorado, da classe artística e do público brasileiro até hoje defendem essas idéias, ignorando a necessidade de produção artística para o alunado e de educação - em seu sentido mais amplo - para os profissionais da dança. As experiências inócuas de laissez-faire em dança que ainda hoje ocorrem em nossas escolas (jogos com panos, cores, nariz de palhaço, "dance e seja feliz") estão provavelmente alicerçadas nos argumentos arcaicos de Laban sobre a educação, na falta de uma visão mais crítica em relação à dança e à educação nos dias de hoje.

Embora em Dança educativa moderna Laban faça constante menção aos benefícios da dança na educação do ser humano "humanizado", dedica quase dois terços de seu livro para explicar, rever e revolver a importância vital no processo educacional criativo da descoberta e aprendizado do fluxo do movimento, de suas possibilidades no espaço, de suas qualidades (esforços), formas e trajetórias. A partir da consciência das possibilidades de movimento, dizia Laban, é que a criação, a transformação, a dissolução de formas e desenhos no "jogo" da dança seriam possíveis (Laban, 1990).

Percebemos que para Laban, a articulação de conteúdos específicos atua como elemento gerador do processo criativo. Infere-se, portanto, que a compreensão corporal e intelectual da linguagem da dança é elemento crucial no processo de educação, quer do indivíduo, como afirma em seu livro, quer do profissional de dança.

Poderíamos, assim, inverter esse olhar pedagogizante que tomou conta das propostas de Laban se entendermos hoje seus princípios não somente como uma proposta de dança na educação/escola, mas, principalmente, de educação na dança. Educar-se em dança necessariamente implica conhecer e apropriar-se corporalmente de suas estruturas formativas (sua 'sintaxe', sua linguagem) e não somente reproduzir seus estilos, códigos, passos, princípios anatômicos e cinesiológicos. O conhecimento da linguagem da dança, ou o que Laban chamou de "coreologia", possibilita um entendimento da dança que compreende a performance, a criação, a apreciação e suas relações com a sociedade (Marques, 1999).

Seria extremamente ingênuo, portanto, trazermos hoje as propostas de Laban para o contexto educacional - profissional ou não sem que dissolvamos e datemos seus princípios filosóficos e educacionais. Ao contrário, suas propostas assumem relevância somente na medida em que são percebidas não como métodos de ensino, mas como subtextos da dança, como linguagem, como conteúdos educacionais. É o que veremos a seguir.

\section{Existe mesmo um "método Laban"?}

Em 1948, com a finalidade de preservar as idéias de Laban, é publicada na Inglaterra a revista The Laban Art of Movement Guild Magazine, 
cuja primeira referência, escrita por Laban, dizia que "a associação não poderá empreender cursos, escolas, negócios com fins lucrativos, nem anunciar diretamente nenhum tipo especial de método" (apud Thornton, 1971, p. 19, ênfase minha).

Método é um caminho, um caminho pelo qual se chega a um resultado, esperado ou não, previsto ou não. Método é um meio, um atalho, uma forma estabelecida de caminhar, de direcionar uma ação, de olhar adiante rumo a um objetivo palpável.

Podemos falar de método (ou métodos) de ensino, de métodos de observação, métodos de análise e interpretação, mas, definitivamente, não podemos falar de "método Laban". Laban, inclusive, era avesso aos métodos e aos caminhos únicos pré-estabelecidos (Lamb, apud Thornton, 1971, p. 19), e tratava de estimular cada pessoa de uma forma diferente, incentivando o movimento, a descoberta pessoal, o desenvolvimento da personalidade de cada um.

Em nenhum de seus livros, e menos ainda em Dança educativa moderna, Laban estabelece caminhos, seqüências, procedimentos para o aprendizado da dança. Para ele, "[...] o professor deve encontrar sua própria maneira de estimular os movimentos e, posteriormente, a dança [...]" (Laban, 1990, p. 33). Do mesmo modo, Laban não nos ensina como observar o movimento humano, porém aponta o que deve e pode ser observado para compreensão da dança, dos movimentos de trabalho, da personalidade dos indivíduos.

Caso tivesse proposto caminho, ou um método - pedagógico, artístico ou de pesquisa - teria estabelecido ele mesmo um paradoxo em sua proposta de libertar o homem de caminhos já traçados, de danças prontas, de movimentos codificados. "Ele queria que suas teorias e descobertas fossem vistas como os primeiros passos na estrada para a compreensão do significado do movimento e não a palavra definitiva sobre o assunto" (Thornton, 1971, p. 20). Laban, acima de tudo, desejava que as pessoas continuassem investigando e experimentando de forma fluida, descobrindo formas pessoais de dançar, de ensinar, de observar e de pesquisar o fluxo do movimento humano - em última instância, permitindo o fluxo da vida (Ibid.).

Apesar de suas colocaçôes e convicções, Laban acaba discutindo em seu livro para pais e educadores algumas posturas metodológicas ditas benéficas ao desenvolvimento integral da criança, em suas múltiplas possibilidades de criação, eximindo-se, no entanto, de ditar métodos de ensino. Laban prefere aconselhar pais e professores sobre atitudes adequadas ao desenvolvimento e cultivo da sensibilidade, da percepção, dos impulsos internos e da expressão individual de cada um. De influência claramente escola-novista, sugere que sejam atentos, que observem, que aprendam junto com os alunos e que, principalmente, não julguem ou interfiram na criação individual de cada um.

Mesmo com ênfase na criação individual e intransferível da movimentação e escolha individual, Laban não deixa em momento algum de estabelecer parâmetros para criação. Como faz questão de lembrar Lisa Ullmann no posfácio de Dança educativa moderna, "de maneira alguma [a dança] deve ser caoticamente livre" (1990, p. 114). Esses parâmetros, no entanto, não são parâmetros metodológicos e sim de conteúdo. A ferramenta de trabalho que Laban oferece aos pais e professores são os temas de movimento, ou seja, a coreologia. Laban oferece os elementos da linguagem para que cada um crie sua aula, seu programa, seu currículo, sua dança, sua vida, enfim.

A ênfase de Laban tanto nos processos criativos em dança quanto na importância da experimentação e da transformação do movimento consciente faz com que, para os desavisados, uma "aula Laban" seja sinônimo irrevogável de uma aula de improvisação ou, para os leigos, uma aula de "expressão corporal". A improvisação em dança, no entanto, não é reduto dos 'labanianos', mas tão somente uma das possibilidades de conhecer seus princípios de movimento. Por outro lado, podemos pensar que os princípios de movimento decodificados por 
Laban podem ser elementos estruturadores de uma improvisação (peso, espaço, forma, tensões espaciais, etc.), na mesma medida que estruturam uma composição coreográfica ou uma aula de técnica codificada, como veremos a seguir.

\section{Uma questão de técnica}

Consciente do poder do movimento e da dança na formação do caráter, da personalidade e da cidadania, Laban propõe, já no primeiro prefácio de Dança educativa moderna, em 1948, que a dança, para alcançar seus objetivos de libertação e desenvolvimento humanos, deveria ser uma "dança livre", ou ainda uma "técnica de dança livre". Buscava com isso diferenciar suas propostas das danças existentes na época, ou seja, do balé clássico e das danças de salão.

Lisa Ullmann, em 1963, acrescenta às idéias de Laban uma explicação do que seria exatamente essa técnica: "uma técnica de dança 'livre', ou seja, liberada de um estilo idealizado segundo normas específicas" (Ullmann 1990, p. 114). Insiste, mais uma vez, que não é por isso que deva ser "caoticamente livre". Para Ullmann, a técnica é necessária à aquisição de experiência, mas deve estar necessariamente ligada à compreensão do conteúdo do movimento. Ou seja, dentro de conceitos específicos determinados e claros - e não de formas externas impostas de fora para dentro -, cada um pode criar e desenvolver sua própria maneira de dançar.

Ainda hoje, das práticas do balé clássico às da nova dança, modelos de corpo e movimento e, portanto, de indivíduo e de sociedade, continuam sendo impressos no mundo a partir das técnicas codificadas de dança. Corpos de bailarinos e leigos continuam tomando formas unificadas, pasteurizando também formas de pensar e de agir em sociedade via aulas de técnica.

Para muitos da área de dança, essas aulas são sinônimos (positivos) de aquisição de habilidades que, praticadas regularmente, podem ser mantidas e usadas como vocabulário específico para os trabalhos de dança (Hodgson \& Preston-
Dunlop, 1990). Ao contrário disso, a "técnica de dança livre" de Laban buscava ampliar esse vocabulário de dança, trazendo da experiência de cada um novos arranjos, caminhos e possibilidades para dançar. Para Laban, conhecer o uso de energia, de peso, das possibilidades do fluxo do movimento no espaço (etc.), era como adquirir um outro tipo de "habilidade", uma habilidade que abre portas e diferencia as pessoas, pois permite a expressão e a comunicação pessoal e intransferível de cada um.

Discussões mais recentes na área de Educação Somática estenderam o conceito de técnica para a dança, propondo-se a trabalhar mais com os "fundamentos" do movimento - que incluem a respiração, o alinhamento, a flexibilidade, entre outros - em detrimento do condicionamento e da codificação do corpo. Em alguns países, os princípios de Laban são tomados como uma prática de Educação Somática, lado a lado das práticas de Feldenkrais, Eutonia, entre outros.

Não é de se estranhar, portanto, que os bailarinos "mais técnicos", intérpretes não criadores da dança, até hoje desconheçam e/ou repudiem as idéias de Laban, não direcionadas para um condicionamento corporal específico, codificado, condicionamento esse supostamente bom para todos aqueles que almejam um lugar ao sol no mundo tradicional da dança.

Contemporaneamente, as propostas de Laban, se entendidas como linguagem, podem ter um papel primordial até mesmo na compreensão e execução das próprias técnicas codificadas, desconstruindo-as. Os estudos de Laban permitem a observação, análise e percepção corporal e intelectual dos elementos de movimento embutidos nos diferentes estilos de dança e, conseqüentemente, dos aspectos sócio-políticoculturais dessa dança. Ou seja, ao estudarmos, vivenciarmos e compreendermos a linguagem da dança, compreenderemos também suas mensagens subliminares, pois a linguagem tem significação. Dessa forma, não mais faremos ingenuamente uma aula de balé, ou de nova dança, ou de flamenco, mas teremos a possibilidade de 
ter uma maior consciência de como essas técnicas estão construindo nossos corpos e nos sugerindo que tipo de cidadania.

\section{Para concluir}

As propostas de dança e ensino de Rudolf Laban, se recontextualizadas, continuam fazendo sentido na formação do artista-docente-cidadão do século XXI. Suas contribuições para a decodificação da linguagem da dança, na arte da performance ou na escola, permitem olhar e viver a dança sob diversos ângulos, de forma relacional, consciente e profunda. Diferentemente do laissezfaire com que foi e ainda é confundido no Brasil, o conhecimento das propostas de Laban nos permite vivenciar, via dança, uma cidadania aberta, crítica, múltipla e transformadora.

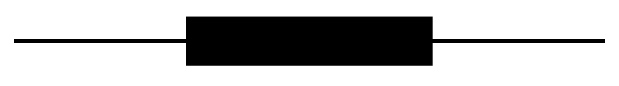

\section{Referências bibliográficas}

HODGSON, J.; PRESTON-DUNLOP, V. Rudolf Laban: an introduction to his work and influence. Londres: Northcote House, 1990.

LABAN, R. Dança educativa moderna. São Paulo: Ícone, 1990.

MARQUES, I. A dança criativa e o mito da criança feliz. Revista Mineira de Educação Física, v. 5, n. 1, p. 28-39, 1997.

. Ensino de dança hoje: textos e contextos. São Paulo, Cortez, 1999.

NAVAS, C.; DIAS, L. Dança moderna. São Paulo: Secretaria Municipal de Cultura, 1992.

PRESTON-DUNLOP, V.; LAHUSEN, S. (ed). A View of German Dance in the Weimar Republic. Londres: Dance Books, 1990.

THORNTON, S. A Movement Perspective of Rudolf Laban. Londres: McDonald \& Evans, 1971.

ULLMANN, L. Posfácio. In: LABAN, R. Dança educativa moderna. São Paulo, Ícone, 1990. 